\title{
Characterization of Organic-inorganic Hybrid Coatings for Corrosion Protection of Galvanized Steel and Electroplated ZnFe Steel
}

\author{
Maria Eliziane Pires de Souza, ${ }^{\mathrm{a}, \mathrm{b} *}, E_{\text {Edith Ariza }}^{\mathrm{b}}$, Margarita Ballester ${ }^{\mathrm{c}}$ Inez Valéria Pagotto Yoshida , \\ Luis Augusto Rocha ${ }^{\mathrm{b}, \mathrm{e}}$, Célia Marina de Alvarenga Freire ${ }^{\mathrm{a}}$ \\ ${ }^{a}$ Faculty Mechanical Engineering, UNICAMP, \\ C.P. 6122, 13083-970 Campinas - SP, Brazil \\ ${ }^{\mathrm{b}}$ Research Centre on Interfaces and Surfaces Performance, \\ University of Minho, 4800-05 Guimarães, Portugal \\ 'Applied Physics Department, Physics Institute, UNICAMP, \\ C. P. 6039, 13081-970 Campinas, SP, Brazil \\ ${ }^{\mathrm{d}}$ Chemistry Institute, UNICAMP, Campinas - SP, Brazil \\ 'Mechanical Engineering Department, University of Minho, 4800-058 Guimarães - Portugal
}

Received: December 2, 2004; Revised: August 22, 2005

\begin{abstract}
The development of hybrids materials has been extensively investigated in recent years. The combination of a wide variety of compositions and production processes had permitted the use of these materials in different applications like coatings for corrosion protection of metals. In this work organic-inorganic hybrid materials have been prepared from the hydrolysis of tetraethylorthosilicate and silanol-terminated polidymetilmetoxysilane using a sol-gel process. These materials have been applied on galvanized steel and on steel electroplated with a $\mathrm{ZnFe}$. In order to evaluate the degradation behavior of these coatings, electrochemical techniques (Electrochemical Impedance Spectroscopy and Potentiodynamic Polarization) were used. EIS data was fitted to an equivalent circuit from which the electrochemical parameters were obtained. Results show a good protective character of the hybrid films, when compared with uncovered specimens. The overall performance of the coating systems appears to be highly dependent on the kind of metallic coating applied to the steel.
\end{abstract}

Keywords: organic-inorganic hybrids, coatings and corrosion

\section{Introduction}

Painted films have been widely used to provide protection and corrosive prevention for metallic surfaces; furthermore, these protective coatings permit the introduction of some properties, such as mechanical strength and hydrofobicity ${ }^{1}$. An industrial coating system may consist of several layers each one having different functions. A chemical-conversion coating of chromate or phosphate is often applied initially to provide a substrate of superior adherence. A primer coating of good surface adherence and inhibitive properties may be required; these improve the durability of the final topcoats, which have maximum resistance to weather conditions ${ }^{2}$.

Nowadays, because of toxicity of chromate ions, environmental legislation has pressured for to prohibit the pre-treatment with chromates. As a consequence alternatives pre-treatments have been researched. Thus, organic-inorganic hybrid films made by sol-gel reaction can be developed as a viable alternative. The low temperature processing conditions of the sol-gel hybrids, and their fast curing behavior enables one to perform coil coating processes and to apply thin film on metal sheets ${ }^{1,3}$.

The development of a hybrid material is based on the incorporation of oligomers and polymers species into the inorganic matrix. Silanol-terminated polymers or oligomers can be incorporated into an oxide network derived from tetraethylorthosilicate ${ }^{4}$. One kind of polymer species utilised like organic component are the polysiloxanes; they are polymers that contain silicon and oxygen atoms at the principal chain and are characterized for three-dimensional siloxanes net with organic substitutes constituting the units that form the net. Polysiloxanes have been developed for use as industrial raw materials such as resins, oils and rubbers, because of their excellent chemical, physical and electrical properties 5 .

The present paper focuses on the corrosion resistance of a solgel derived organic-inorganic hybrid coating on steel galvanized and $\mathrm{ZnFe}$ electrocoated steel without chromate pre-treatment. The hybrid film coatings were made from tetraethylorthosilicate (TEOS) and Polidymetilmetoxysilane (PDMS) using a sol-gel process. Electrochemical techniques, such as EIS and potentiodynamic polarization, were used to monitor the corrosion behavior of the coating system in a corrosive electrolytic medium. Results were confronted with samples without resin coating to verify the effectiveness of this material. It was demonstrated that the hybrid coating could significantly enhance the corrosion behavior of the studied substrates and the differences between the uncoated surfaces appears to be an important influence upon the results.

\section{Experimental Procedure}

The experimental procedure was divided in three parts: Preparation of hybrids films, application of the coating upon the substrates and electrochemical characterization. The utilised substrates were: galvanized steel and electroplated $\mathrm{ZnFe}$ steel and their characteristics are presented in Table 1 . None post plating passivation treatments was made on the substrates. 


\subsection{Preparation of hybrids films}

Sol-gel process was used in the hybrid films preparation. A proportion of 50\% in weight of each component, TEOS and PDMS-OH, was mixed with Dibutylthin diacetate, catalytic, in the proportion of $0.2 \%$ weight. This blend was mixed during 15 minutes approximately, until getting an ideal viscosity to application on the substrates.

\subsection{Application of the coating}

Before coat application, the substrates were cleaned in order to remove any kind of grease. The hybrid film was applied with a baton that spread the covering upon the plates. A box specially designed and dimensioned was used to obtain a resin coating with $25 \mu \mathrm{m}$ of thickness. The curing process was carried out during 12 hours at a temperature of $95^{\circ} \mathrm{C}$. Samples are referred as $\mathrm{Zn}$ and $\mathrm{ZnFe}$, corresponding to the galvanized and electroplated $\mathrm{ZnFe}$ specimens and as $\mathrm{Zn} / \mathrm{C}$ and $\mathrm{ZnFe} / \mathrm{C}$ when they are coated with hybrid film.

\subsection{Electrochemical characterisation}

The electrochemical tests were performed at room temperature in a solution of $3 \%$ in weight of $\mathrm{NaCl}$. A potentiostat-galvanostat $\mathrm{PGZ}$ 100 Voltalab (Radiometer, Denmark), controlled by the VoltaMaster-4 software, was used in the open circuit potential $\left(\mathrm{E}_{\text {corr }}\right)$, Electrochemical Impedance Spectroscopy (EIS), and potentiodynamic polarisation measurements. A three-electrode cell arrangement was used in all experiments. The exposed area of working electrode was $1.86 \mathrm{~cm}^{2}$. The reference electrode was a saturated calomel electrode (SCE) and the counter electrode was a wire of Platinum. The $\mathrm{E}_{\text {corr }}$ was monitored during 60 minutes, after which samples were anodically polarised in the range -1700 to $1000 \mathrm{mV}$ at a scan rate of $2 \mathrm{mV} . \mathrm{s}^{-1}$.

EIS measurements were made at increasing exposure times, until 3 days of exposure. The impedance spectra were ranged from $10^{5}$ to $10^{-2} \mathrm{~Hz}$, using an a.c. signal imposed with amplitude of $10 \mathrm{mV}$.

The impedance spectra were analysed using ZView software and an electrochemical equivalent circuit model was used to adjust the EIS experimental data and to evaluate the behavior of coatings in the corrosive environment. The chi-squared and sum of squares were used to judge the quality of the fit.

Scanning Electron Microscopy (SEM) was used to study the morphology of coatings. Additionally, the chemical composition was evaluated in an energy dispersive spectrometer (EDS). Surfaces of resin coatings were analysed at the initial conditions and after EIS tests.

\section{Results and Discussion}

\subsection{Electrochemical impedance spectroscopy test}

Some characteristics of coatings, such as corrosion behavior, porosity, solution absorption and/or film delamination, can be predict by Electrochemical Impedance Spectroscopy ${ }^{6,7}$. The monitoring of the time dependence of the electrochemical impedance of the coated samples, exposed to the electrolytic solution, allowed the study of the protective character of each coating system to be compared. It is well known that equivalent electrical circuits can be used to explain the electrochemical impedance data obtained by the EIS tests. These

Table 1. Substrates used and their characteristics.

\begin{tabular}{cc}
\hline Substrate & Metallic coating thickness $(\mu \mathrm{m})$ \\
\hline Galvanized steel & 5 \\
Electroplated ZnFe steel & 5 \\
\hline
\end{tabular}

models use a combination of resistance, capacitance and other electrical elements, which have a clear physical meaning, related with the response of the electrochemical system ${ }^{7}$. In this work two equivalent electrical circuit models were used and were presented in Figure 1. Circuit 1, Figure 1a, is a simple circuit where the coating capacitance $\left(\mathrm{C}_{\mathrm{c}}\right)$ and the polarization resistance $\left(\mathrm{R}_{\mathrm{p}}\right)$ are represented; this circuit was used to adjust all results from sample $\mathrm{Zn} / \mathrm{C}$, and those regarding the first eight hours of immersion in sample $\mathrm{ZnFe} / \mathrm{C}$. On the other hand, circuit 2, Figure 1b, was used to fit the results of sample $\mathrm{ZnFe} / \mathrm{C}$, after eight hours of immersion, and the uncoated samples ( $\mathrm{Zn}$ and $\mathrm{ZnFe}$ ). In this last circuit $\mathrm{R}_{\mathrm{po}}$ is the pore resistance of coating, $\mathrm{C}_{\mathrm{c}}$ is the coating capacitance, $\mathrm{R}_{\mathrm{ct}}{ }_{\mathrm{po}}$ is the charge-transfer resistance, $\mathrm{C}_{\mathrm{DL}}$ is the double-layer capacitance at the coating/solution interface. In both circuits $\mathrm{R}_{\mathrm{e}}$ is the electrolytic resistance. All the capacitances shown in the equivalent electrical circuit are mathematically modelled using a constant phase element (cpe); this element represents all the frequency dependent electrochemical phenomena ${ }^{8}$. The EIS experimental data were successful adjusted to these circuits.

In Figure 2 the open circuit potential $\left(\mathrm{E}_{\text {corr }}\right)$ obtained for all samples is presented. As it can be observed, after one hour of immersion, the $\mathrm{ZnFe}$ - coated steel sample exhibits a $\mathrm{E}_{\text {corr }}$ slightly higher than that of the galvanized steel ( $\mathrm{Zn}$ ). However, during immersion the behavior of the $\mathrm{ZnFe}$ sample appears to approach that of the $\mathrm{Zn}$, this being an indication of a similar corrosion tendency for both samples. The hybrid film coated samples $(\mathrm{Zn} / \mathrm{C}$ and $\mathrm{ZnFe} / \mathrm{C}$ ) reveal a corrosion potential substantially higher than their respective substrates, showing that these coating behave like a barrier, decreasing the tendency to corrosion of the substrates.

Figures 3 and 4 present the Bode plots resulted from the EIS tests, in which a comparison between uncoated and coated samples is made.
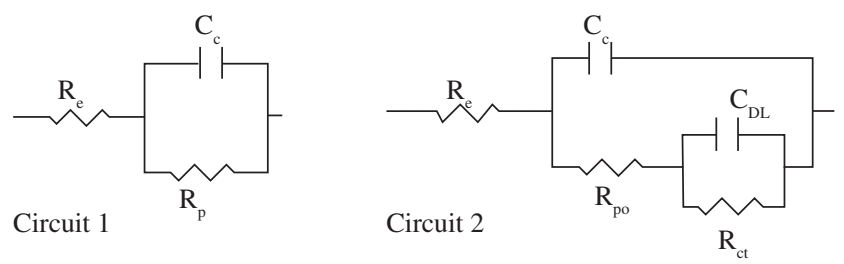

Figure 1. Equivalent electrical circuits utilised to fit EIS data.

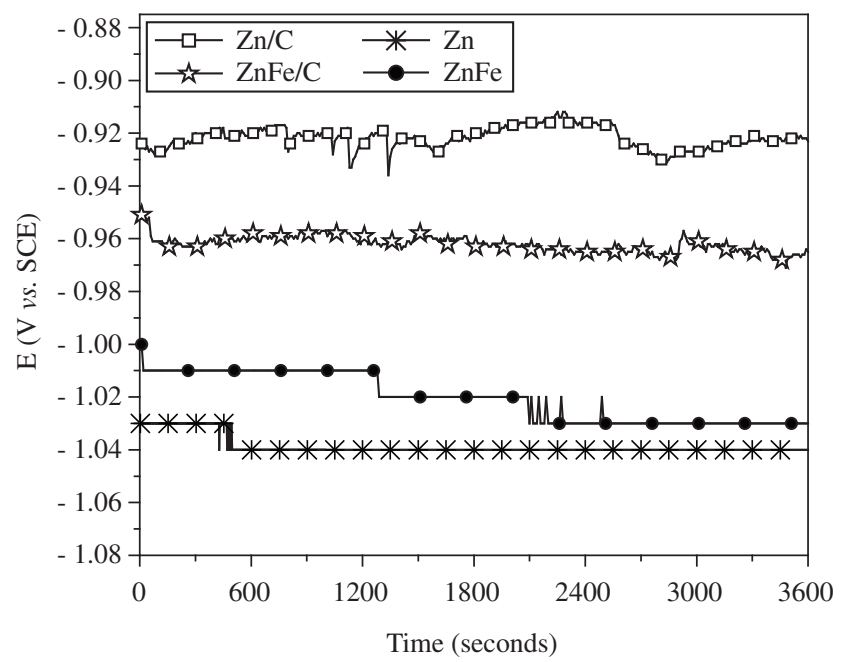

Figure 2. Evolution of open circuit potential with the time. in $\mathrm{Zn}, \mathrm{ZnFe}, \mathrm{Zn} / \mathrm{C}$ and $\mathrm{ZnFe} / \mathrm{C}$ systems. 


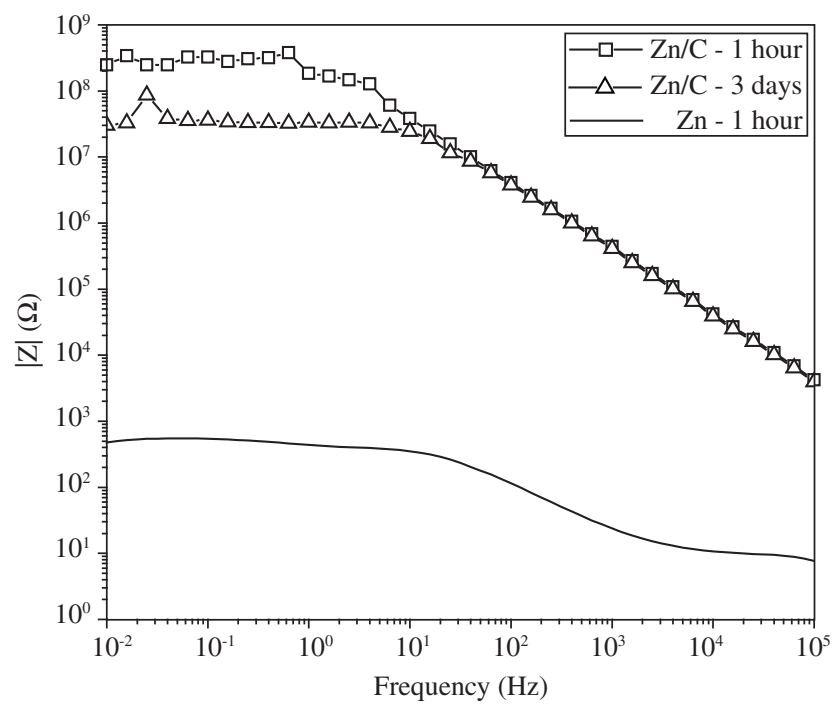

(a)

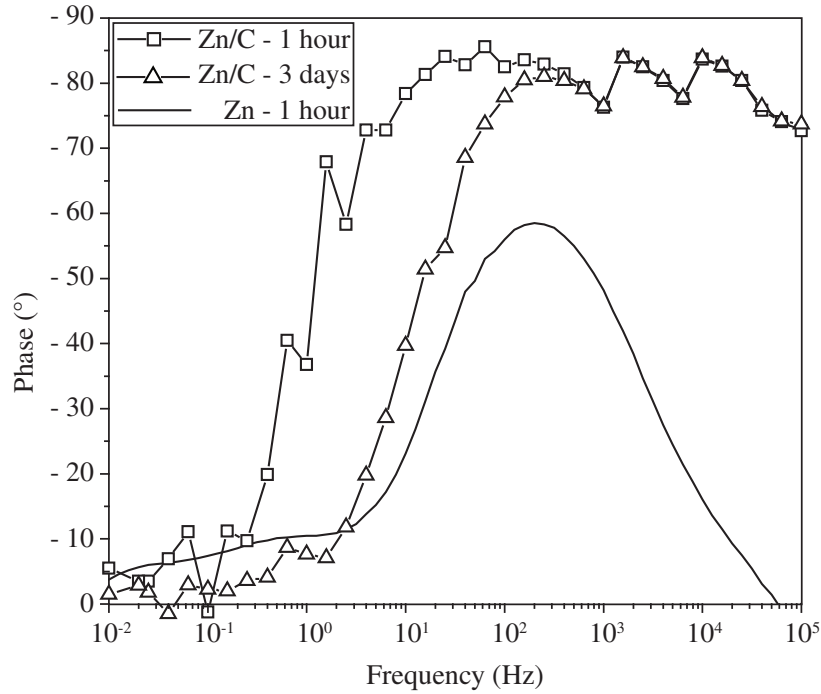

(b)

Figure 3. Representative Bode plots obtained in substrate $\mathrm{Zn}$ and coated $\mathrm{Zn} / \mathrm{C}$ samples, after 1 hour and 3 days of immersion in $3 \% \mathrm{NaCl}$ solution: a) Bode $\mathrm{Z}$; and b) Bode Phase.

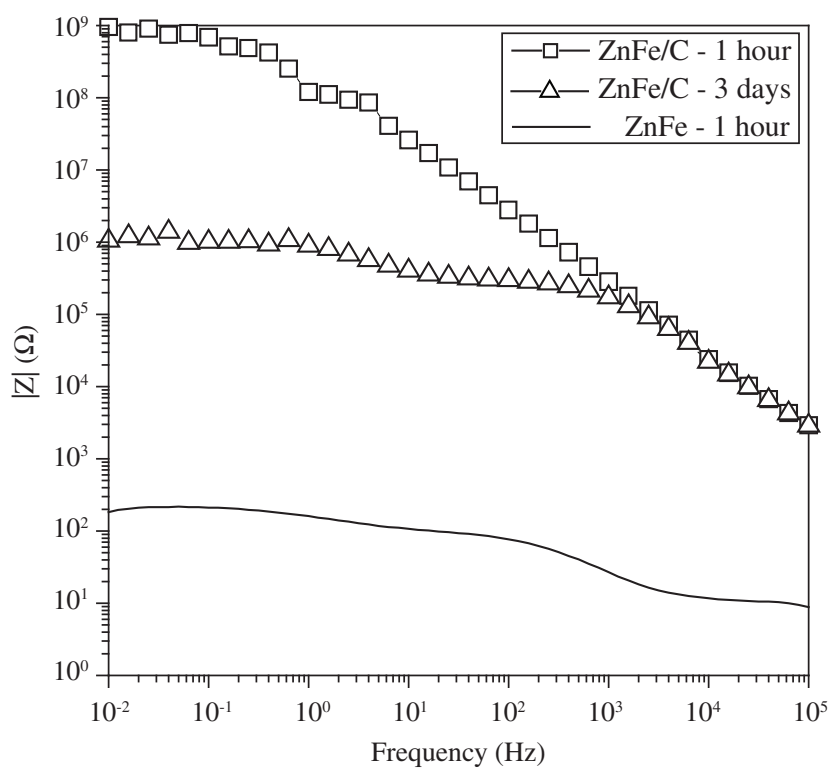

(a)

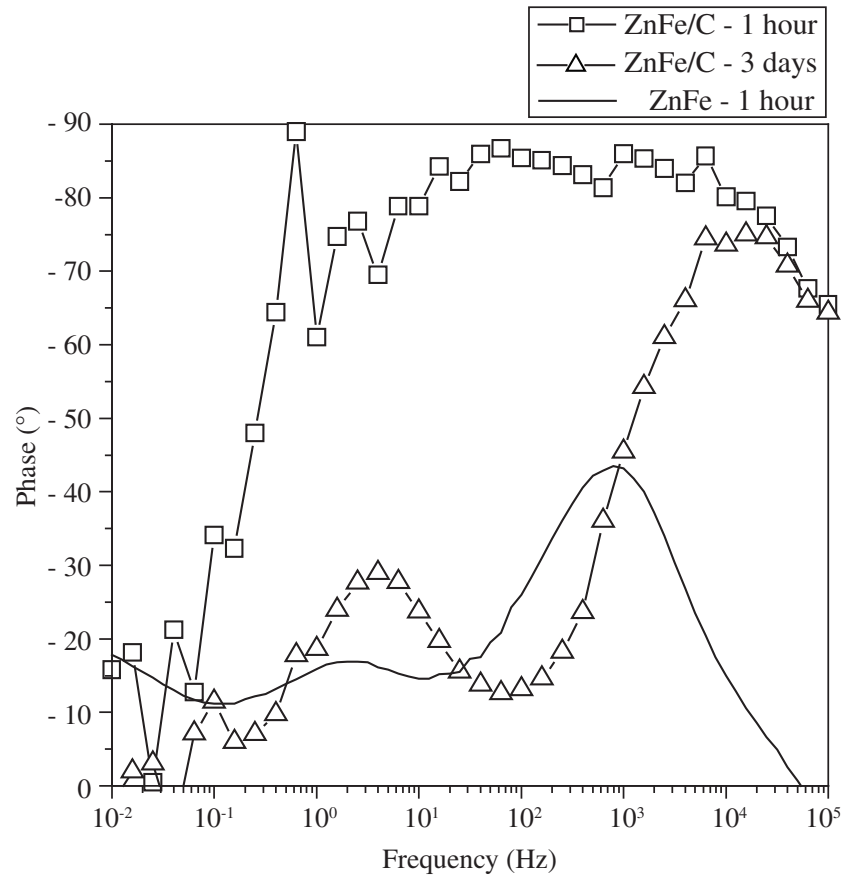

(b)

Figure 4. Representative Bode plots obtained in substrate $\mathrm{ZnFe}$ and coated $\mathrm{ZnFe} / \mathrm{C}$ samples, after 1 hour and 3 days of immersion in $3 \% \mathrm{NaCl}$ solution: a) Bode Z; and b) Bode Phase.

The first remark to be done refers to the barrier against corrosion provided by hybrid films. As it can be observed in Figure 3a and 4a, after one hour of immersion coated samples present impedance modulus (|Z|) values, at low frequencies ranges, several decades higher $\left(10^{-8} \Omega\right.$ for $\mathrm{Zn} / \mathrm{C}$ sample and $10^{-9} \Omega$ for $\mathrm{ZnFe} / \mathrm{C}$ sample) than that found at the same immersion time in the uncoated samples (approximately $10^{-2} \Omega$ for both, $\mathrm{Zn}$ and $\mathrm{ZnFe}$ samples). Besides, phase angles approaching $90^{\circ}$, at high frequencies, are indicative of a capacitive behavior of the coatings (see Figure $3 b$ and $4 b$ ).

Also, as it can be seen in Figure $3 \mathrm{a}$ and $4 \mathrm{a}$, after the third day of immersion the $|Z|$ values of the resin coated samples remains high $\left(10^{-7} \Omega\right.$ for $\mathrm{Zn} / \mathrm{C}$ sample and $10^{-6} \Omega$ for $\mathrm{ZnFe} / \mathrm{C}$ sample), indicating that the hybrid film continues offering a good corrosion protection. Nevertheless, in the $\mathrm{Zn} / \mathrm{C}$ sample a slight decrease in the $|\mathrm{Z}|$ values is observed, while in the $\mathrm{ZnFe} / \mathrm{C}$ sample the $|\mathrm{Z}|$ values diminishes ca. three decades, suggesting a degradation of the protective properties of the hybrid film upon $\mathrm{ZnFe}$ substrate. This fact can be confirmed by a second relaxation time observed at the low frequencies region, as it can be seen in Figure 4b.

According to some authors, the evaluation of coating capacitance $\left(\mathrm{C}_{\mathrm{c}}\right)$ can be associated to water uptake or the entry of electrolyte into the coating ${ }^{6,9,10}$. In Figure 5 the dependence of the $C_{c}$ with the immer- 
sion time is presented. Firstly, the $\mathrm{C}_{\mathrm{c}}$ values for the $\mathrm{Zn} / \mathrm{C}$ and $\mathrm{ZnFe} / \mathrm{C}$ are always lower than the values calculated for the samples without resin ( $\mathrm{Zn}$ and $\mathrm{ZnFe}$ ), indicating a good protective character of the resin over the substrate. Also, as it can be observed in the figure, $\mathrm{C}_{c}$ for the $\mathrm{Zn} / \mathrm{C}$ samples maintains very stable, throughout the immersion time, this being an indication of the maintenance of good protective properties of the hybrid film coating. Regarding the $\mathrm{ZnFe} / \mathrm{C}$ sample, $\mathrm{C}_{\mathrm{c}}$ values show a decline after eight hours of immersion, which can be attributed to the transition from one to two relaxation time; in other words, the surface of samples presents, from this moment on, two capacitances, one related to film hybrid coating (at high frequency ranges) and another $\left(\mathrm{C}_{\mathrm{DL}}\right)$ associated a process that occur in the interface coating/ $\mathrm{ZnFe}$ (at low frequency ranges). This double-layer capacitance $\left(\mathrm{C}_{\mathrm{DL}}\right)$ is related to the area where the delamination or corrosion occurs ${ }^{6}$, what means that hybrid film upon $\mathrm{ZnFe}$ substrate presents the lowest corrosion protection, due to the electrolyte that penetrate through the coating more easily.

In Figure 6 the evolution of polarisation resistance $\left(R_{p}\right)$ as function of immersion time is presented. These values were extracted from the fitting of EIS experimental data and correspond to sum of $\mathrm{R}_{\mathrm{po}}$ and $\mathrm{R}_{\mathrm{ct}}$. The protective characteristics of hybrid films can be confirmed by the

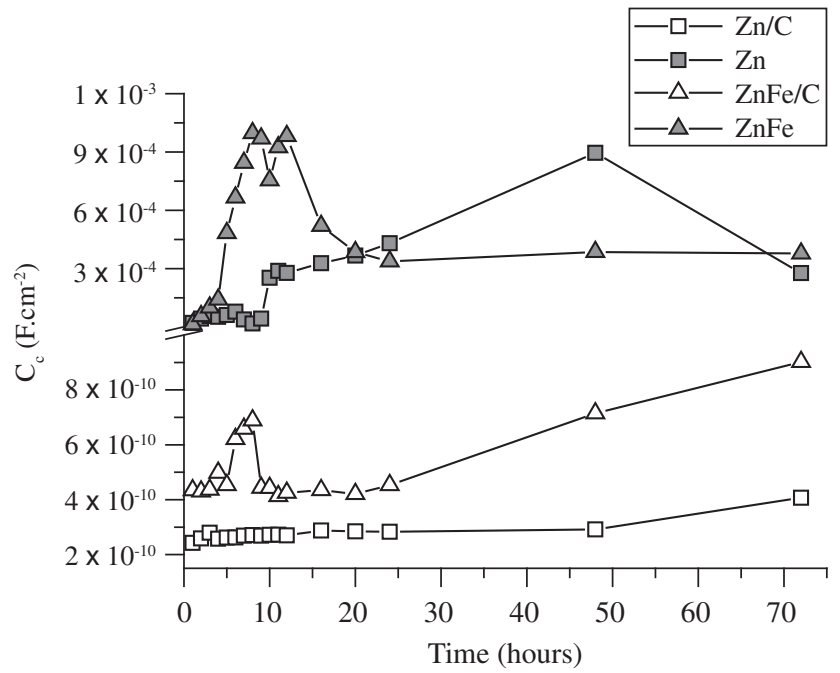

Figure 5. Time dependence of Coating capacitance for all samples.

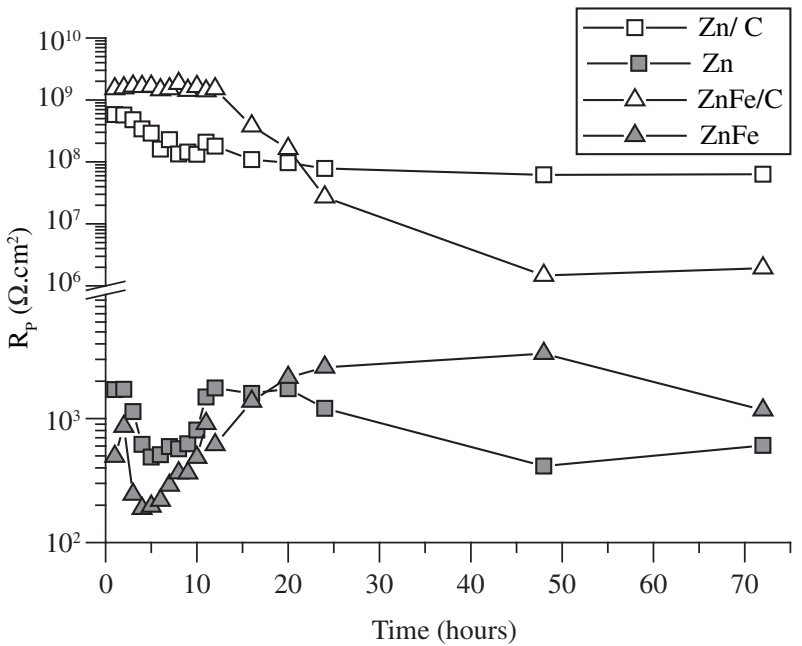

Figure 6. Evolution of polarisation resistance with time for all systems (coated and uncoated samples). high values of $\mathrm{R}_{\mathrm{p}}$ exhibited by samples $\mathrm{Zn} / \mathrm{C}$ and $\mathrm{ZnFe} / \mathrm{C}$. However, the polarisation resistance decreases for both samples during the immersion time, indicating an increasing ionic conductivity for the coating and a low protective capacity ${ }^{11}$. In the first moments of immersion, $\mathrm{R}_{\mathrm{p}}$ for the $\mathrm{ZnFe} / \mathrm{C}$ sample has higher values $\left(10^{9} \Omega . \mathrm{cm}^{2}\right)$ than that calculated for the $\mathrm{Zn} / \mathrm{C}$ sample and remains nearly constant with the increasing time. However, after twelve hours of immersion an abrupt decrease was observed and at the end of three days of immersion the $\mathrm{R}_{\mathrm{p}}$ values for $\mathrm{ZnFe} / \mathrm{C}$ coating comes to a value near $10^{6} \Omega . \mathrm{cm}^{2}$, almost two decades lower than that of the $\mathrm{Zn} / \mathrm{C}$ sample. These results shows that the hybrid films applied on galvanized substrate have a better protective behavior and a greater stability, since the $\mathrm{R}_{\mathrm{p}}$ values of sample $\mathrm{Zn} / \mathrm{C}$ remain in the range of $10^{9}-10^{8} \Omega . \mathrm{cm}^{2}$ and almost constant after sixteen hours of immersion. In comparison, in uncoated systems ( $\mathrm{Zn}$ and $\mathrm{ZnFe}) \mathrm{R}_{\mathrm{p}}$ values ranging between $10^{2}$ and $10^{3} \Omega . \mathrm{cm}^{2}$ were found.

\subsection{Potentiodynamic polarisation test}

Representative potentiodynamic polarisation curves expressing the corrosion behavior of the samples are presented in Figure 7. A first remark to be made refers to the anodic polarisation curves for $\mathrm{Zn} / \mathrm{C}$ and $\mathrm{ZnFe} / \mathrm{C}$ samples. Both curves display a passive plateau with passive current densities smaller than their respective substrates. The calculated corrosion current densities are plotted in Figure 8. The smallest corrosion current density value found, corresponds to the $\mathrm{Zn} / \mathrm{C}$ sample, confirming the better protective behavior to hybrid film upon galvanized steel, indicated by the EIS experiments (high $\mathrm{R}_{\mathrm{p}}$ values and low $\mathrm{C}_{\mathrm{c}}$ values). As it can be seen in Figure 7, the passive current density for the hybrid film coated samples $(\mathrm{Zn} / \mathrm{C}$ and $\mathrm{ZnFe} / \mathrm{C}$ ) are ca. 2 decades lower than that of the $\mathrm{Zn}$ and $\mathrm{ZnFe}$ samples, respectively, this being a strong indication of the protective character of the hybrid film.

Table 2 shows a comparison between $\mathrm{R}_{\mathrm{p}}$ and $\mathrm{i}_{\text {corr }}$ for the different samples. As expected a high $\mathrm{R}_{\mathrm{p}}$ corresponds to a lower corrosion current density. The protection efficiency, $\mathrm{P}$, of the hybrid film coating on the galvanized and $\mathrm{ZnFe}$ electroplated steel substrates can be calculated by using equation $1^{1}$. Where $\mathrm{i}^{0}$ corr and $\mathrm{i}_{\text {corr }}$ denote corrosion current density of the substrate and coated samples, respectively.

$$
\mathrm{P} \%=100\left(1-\mathrm{i}_{\text {corr }} / \mathrm{i}_{\text {corr }}^{0}\right)
$$

The corrosion protection efficiency of hybrid film upon galvanized was found to be $99 \%$ and to hybrid film on $\mathrm{ZnFe}$ was $91 \%$.

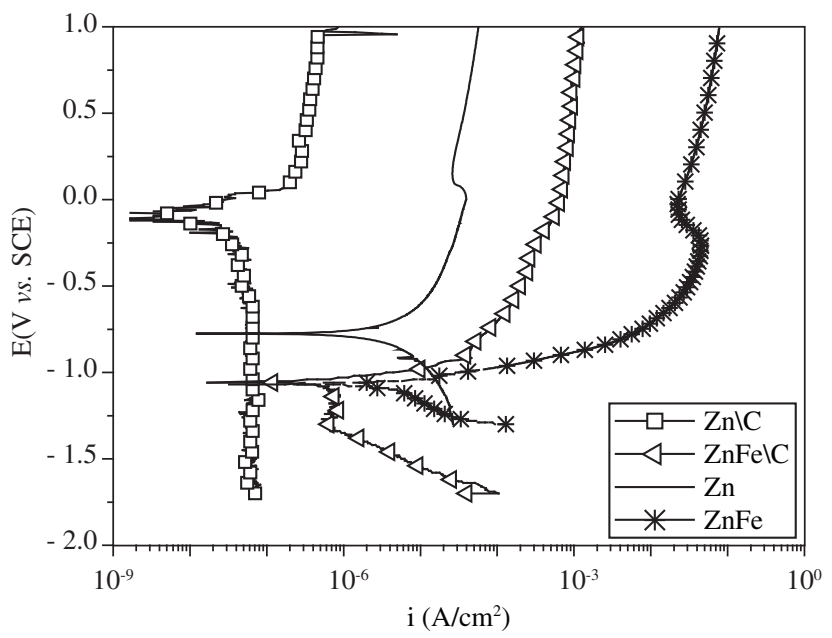

Figure 7. Potentiodynamic polarization curves of coated and uncoated samples. 
The surfaces of samples after the three days of immersion in the saline solution did not show significant modifications on the surface after. The coatings appear to be very smooth and by EDS analysis it was not possible to identify the presence of any corrosion products at the surfaces of samples.

In fact, both EIS and potentiodynamic polarization results indicate that the behavior of the hybrid-coated samples is a consequence of the events happening at the hybrid film/substrate interface. Thus, as referred above, the $\mathrm{ZnFe} / \mathrm{C}$ sample, although presenting a superior corrosion resistance in the beginning of the tests, during immersion these values have a tendency to decrease. The difference between the two substrates can be used to explain these results. Galvanized substrate presents a better behavior in terms of corrosion, what can be associated the better performance of hybrid film coating on this substrate.

In Figure 8 cross-sections representative of both hybrid-coated systems are presented. As it can be seen, in both systems the hybrid film coating appears to be very compact, and no open pores can be detected. However, the observation of the hybrid film/substrate interface reveals a defective adhesion of the coating to the $\mathrm{ZnFe}$ sample, Figure $8 b$, which might lead to accumulation of electrolyte, in case of its penetration through the coating. In another hand, the interface hybrid film/substrate to sample $\mathrm{Zn} / \mathrm{C}$, Figure $8 \mathrm{a}$, presents very homogeneous, without any points indicative of a lost in an adhesion. These images reinforce the results obtained by electrochemical tests;

Table 2. Values of $R_{p}$ and $i_{\text {corr }}$ for all samples.

\begin{tabular}{lccl}
\hline Sample & $\mathrm{R}_{\mathrm{P}}\left(\Omega . \mathrm{cm}^{2}\right)$ & $\mathrm{R}_{\mathrm{p}}\left(\Omega . \mathrm{cm}^{2}\right)$ & $\mathrm{i}_{\text {CORR }}\left(\mu \mathrm{A} / \mathrm{cm}^{2}\right)$ \\
& 1 hour & 3 days & \\
\hline $\mathrm{Zn}$ & 1710.5 & 630.6 & 1.5 \\
$\mathrm{ZnFe}$ & 314.5 & 1232.0 & 2.9 \\
$\mathrm{Zn} / \mathrm{C}$ & $5.8 \times 10^{8}$ & $6.3 \times 10^{7}$ & $2.6 \times 10^{-3}$ \\
$\mathrm{ZnFe} / \mathrm{C}$ & $1.5 \times 10^{9}$ & $1.4 \times 10^{6}$ & $2.5 \times 10^{-1}$ \\
\hline
\end{tabular}

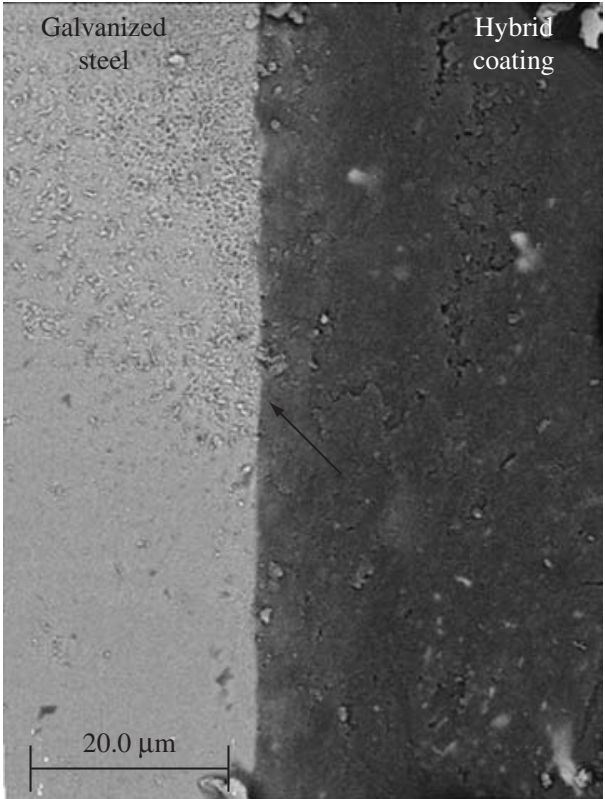

(a) the behavior of hybrid film upon galvanized steel is better than upon $\mathrm{ZnFe}$ electroplated steel.

Figure 6 shows that $R_{p}$ values to galvanized are higher than the values to $\mathrm{ZnFe}$ electroplated steel, this characteristic can exert influence upon samples with film hybrid coating in terms of maintenance of the properties. Another important factor could be the structure of coatings and the kind of interactions between the substrate surface and coating hybrid. However, the evaluation between the structure and the properties of coatings films has not established yet and are part of future researches.

\section{Conclusions}

The corrosion resistance of a sol-gel derived organic-inorganic hybrid coating on galvanized steel and $\mathrm{ZnFe}$ electrocoated steel, immersed in a $3 \% \mathrm{NaCl}$ solution was studied by electrochemical spectroscopy impedance (EIS) and potentiodynamic polarisation techniques. It was well demonstrated that the EIS combined with the electrochemical standard technique are powerful methods to characterize the corrosion behavior and the efficiency of hybrid coatings.

These hybrid coatings, prepared by sol-gel processes, applied upon galvanized steel and $\mathrm{ZnFe}$ electrocoated steel substrates demonstrated ability of providing supplemental corrosion protection by forming a physical barrier. However the galvanized steel coated samples have shown to possess better corrosion resistance than $\mathrm{ZnFe}$ coated samples. It was found that differences on the response at the substrate/hybrid film interface might be responsible for this different behavior.

\section{Acknowledgments}

The authors gratefully acknowledgments to Coordenação de Aperfeiçoamento de Pessoal de Nível Superior (CAPES), to Conselho Nacional de Desenvolvimento Cientifico e Tecnológico (CNPq) of Brasil, and to Fundação para a Ciência e a Tecnologia (FCT), Portugal - project - SFRH/BPD/5518/2001 by the financier support.

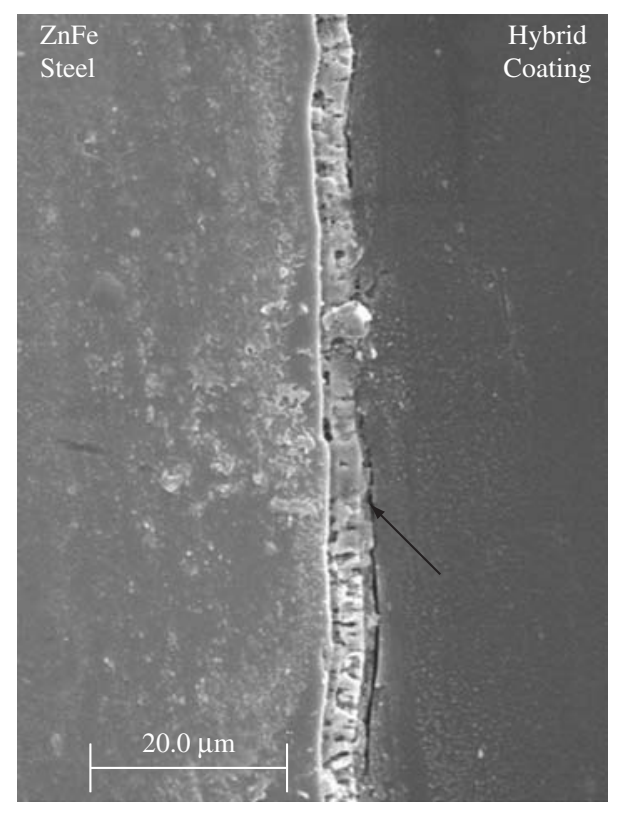

(b)

Figure 8. a) SEM micrographs of the cross section of $\mathrm{Zn} / \mathrm{C}$; and b) $\mathrm{ZnFe} / \mathrm{C}$. 


\section{References}

1. Chou TP, Chandrasekaran C, Limmer SJ, Seraji S, Wu Y, Forbess MJ, et al. Organic-inorganic hybrid coatings for corrosion protection. Journal of Non-Crystalline Solids. 2001; 290(2-3):153-162.

2. Jones D A. Principles and prevention of corrosion. 2 ed. USA: PrenticeHall, 1996.

3. Schottner G. Hybrid sol-gel derived polymers: applications of multifunctional materials. Chem Mater. 2001; 13:3422-3435.

4. Téllez L, Rubio J, Rubio F, Morales E, Oteo J L. Syntesis of inorganic-organic hybrid materials from TEOS, TBT and PDMS. Journal of Materials Science. 2003; 38(8):1773-1780.

5. Abe Y, Kagayama K, Takamura N, Gunji T, Yoshihara T, Takahashi N. Preparation and properties of polysilsesquioxanes. Function and characterization of coating agents and films. Journal of Non-Crystalline Solids. 2000; 261(1-3):39-51.
6. McIntyre J M, Pham H Q. Electrochemical impedance spectroscopy; a tool for organic coatings optimisations. Progress in Organic coatings. 1996; 27(1-4):201-207.

7. Bonora P, Deflorian F, Fedrizzi L. Electrochemical impedance spectroscopy as a tool for investigation underpaint corrosion. Electrochimica Acta. 1996; 41(7-8):1073-1082.

8. Macdonald J R. Impedance Spectroscopy, 1 ed. New York, USA: John Wiley \& Sons, 1987.

9. Bajat J B, Miskovic-Stankovic V B, Kacarevic-Popovic Z. The influence of steel surface modification by electrodeposited $\mathrm{Zn}-\mathrm{Fe}$ alloys on the protective behavior of epoxi coating. Progress in Organic Coatings. 2003; 47(1):49-54.

10. Tsai C H, Mansfeld F. Determination of coating deterioration with EIS 2. Development of a method for field testing of protective coatings. Corrosion. 1993; 49(9):726-737.

11. Maksimovic M D, Miskovic-Stankovic V B. The corrosion behavior of epoxy resin electro coated steel. Corrosion Science. 1992; 33(2):271-279. 